\title{
Solution Structure of Psb27 from Cyanobacterial Photosystem II
}

\author{
Peter D. Mabbitt ${ }^{1}$, Gilles J. P. Rautureau ${ }^{2}$, Catherine L. Day ${ }^{1}$, Sigurd M. Wilbanks ${ }^{1}$, \\ Julian J. Eaton-Rye ${ }^{1, *}$, and Mark G. Hinds ${ }^{2, *}$ \\ ${ }^{1}$ Department of Biochemistry, University of Otago, Dunedin 9054, New Zealand \\ ${ }^{2}$ Walter and Eliza Hall Institute of Medical Research, Parkville 3052, Australia
}

*To whom correspondence should be addressed. Tel: +64 34797865 (Eaton-Rye); +61 3 93452537 (Hinds). Fax: +64 34797866 (Eaton-Rye); +61 393470852 (Hinds). Email: julian.eaton-rye@otago.ac.nz; mhinds@wehi.edu.au 


\section{MATERIALS AND METHODS}

Cloning and Expression. The coding sequence for residues 1 to 110 of the mature Psb27 protein was amplified by PCR from genomic Synechocystis sp. PCC 6803 DNA using the forward and reverse primers: 5'-ACAGGATCCTGCGACAGCGGCACAGGACTC-3' and 5'-ATAGGATCCTCACACGCCCCGTTGAATG-3', respectively, with both containing BamHI recognition sites. The Psb27 cDNA was digested with BamHI and ligated into the pGEX-6P-3 plasmid (GE Healthcare, Piscataway, NJ) that had been cut with the same restriction enzyme. The resulting plasmid was then used as the template for amplification using a forward primer complementary to the $3 \mathrm{C}$ protease recognition site from pGEX-6P-3 (5'-TCGGATCTAGAGGTTCTGTTCCAGGG-3') and a reverse primer complementary to psb27, and including an XhoI recognition site (5'-GTATCCTCGAGTCACACGCCCCGTTC AATGGA-3'). Amplified product was digested with $X h o \mathrm{I}$ and ligated into the pENTR-11 vector (Invitrogen, Carlsbad, CA) that had been digested with XhoI and XmnI. A clone of the resulting plasmid (pGSZ-11) was isolated and the psb27 gene was sequenced in both the forward and reverse directions. The pGSZ-11 vector was recombined in a Clonase reaction (Novagen, La Jolla, CA) with a modified pET32a vector (Novagen, La Jolla, CA) containing bacteriophage $\lambda$ recombination sites (attR) flanking a $c c d B$ gene (Gateway cassette; Novagen, La Jolla, CA). The identity of the resulting plasmid (pGSZ-32a) was confirmed by restriction digestion. This plasmid encodes thioredoxin followed by 6 histidine residues, a PreScission protease cleavage site (LEVLFQ $\&$ GP) and mature Psb27 (THX-(His) ${ }_{6}$-X-Psb27). Cleavage resulted in five residues fused to the N-terminus of the mature Psb27 protein.

Escherichia coli BL21 (DE3) cells transformed with the pGSZ-32a vector were grown at $37^{\circ} \mathrm{C}$ in Lysogeny broth, or in minimal medium containing ${ }^{15} \mathrm{~N}$-ammonium chloride or ${ }^{15} \mathrm{~N}$-ammonium chloride and ${ }^{13} \mathrm{C}$-glucose, and supplemented with $50 \mu \mathrm{g} / \mathrm{mL}$ of ampicillin. When cultures reached an optical density at $600 \mathrm{~nm}$ of $0.6,500 \mu \mathrm{M}$ isopropylthio-D- 
galactopyranoside was added in order to induce the expression of recombinant protein. Cells were further incubated for $4 \mathrm{~h}$ at $37^{\circ} \mathrm{C}$, harvested by centrifugation at $8,000 \mathrm{~g}$ for $10 \mathrm{~min}$ and then resuspended in buffer A $(20 \mathrm{mM}$ sodium phosphate $\mathrm{pH} 7.6,500 \mathrm{mM}$ sodium chloride, $20 \mathrm{mM}$ imidazole).

Protein Purification. Bacteria were disrupted by sonication then centrifuged for $20 \mathrm{~min}$ at $8000 \mathrm{~g}$ to pellet cell debris. The soluble fraction was recovered and filtered $(0.2 \mu \mathrm{m})$ before application to a $5 \mathrm{~mL}$ nickel immobilized metal affinity chromatography (IMAC) column (GE Healthcare, Piscataway, NJ) equilibrated with $25 \mathrm{~mL}$ of buffer A. After washing the column with $50 \mathrm{~mL}$ of buffer A, protein was eluted with $25 \mathrm{~mL}$ of buffer B (20 mM sodium phosphate $\mathrm{pH}$ 7.6, $500 \mathrm{mM}$ sodium chloride, $100 \mathrm{mM}$ imidazole). Dithiothreitol (DTT) (1 $\mathrm{mM}$ ) and PreScission protease were added to the fractions that contained THX-(His) $)_{6}-\mathrm{X}-$ Psb27 in order to remove the N-terminal thioredoxin hexa-histidine tag. After overnight incubation samples were diluted with $20 \mathrm{mM}$ sodium phosphate $\mathrm{pH}$ 7.6, $500 \mathrm{mM}$ sodium chloride to an imidazole concentration of $20 \mathrm{mM}$ then concentrated to $5 \mathrm{~mL}$ using a $10 \mathrm{kDa}$ molecular weight cut-off filter (GE Healthcare, Piscataway, NJ). To separate Psb27 from the hexa-histidine tagged thioredoxin, the sample was applied to a $5 \mathrm{~mL}$ IMAC column (GE Healthcare, Piscataway, NJ). The flow through contained Psb27 and was concentrated to 5 $\mathrm{mL}$ as before, and then applied to a Superdex-75 16/60 size exclusion column (GE Healthcare, Piscataway, NJ) equilibrated with degassed buffer C (20 mM sodium phosphate, $\mathrm{pH}$ 6.7, $50 \mathrm{mM}$ sodium chloride). Following addition of $5 \mathrm{mM}$ Tris (2-carboxyethyl)phosphine hydrochloride (TCEP) the fractions that contained Psb27 were concentrated. Samples were stored frozen at $-80^{\circ} \mathrm{C}$. Protein purity was checked by SDS-PAGE according to the method of Bollag and co-workers $(S 1)$ using $12 \%$ acrylamide with a $37.5: 1$ ratio of cross-link to monomer. 
Circular Dichroism and Light Scattering. CD Spectra were acquired on an OLIS DCM-10 circular dichroism spectrophotometer. Pure Psb27 (0.3 mg/mL) buffered with 20 $\mathrm{mM}$ sodium phosphate/citrate $\mathrm{pH} 3.5,5.5,7.5$ or Tris-phosphoric acid $\mathrm{pH} 9.0$ was analyzed in a $1 \mathrm{~mm}$ pathlength cuvette. The molecular mass of purified Psb27 (14 mg/mL and $1 \mathrm{mM}$ DTT) was determined using a Superdex-75 10/30 column connected to a DAWN8+ multiple angle light scattering (MALS) detector (Wyatt Technology, Santa Barbara, CA) and refractive index detector. Data were collected every $0.5 \mathrm{~s}$ at a flow rate of $0.5 \mathrm{~mL} / \mathrm{min}$. The column was equilibrated with $20 \mathrm{mM}$ sodium phosphate $\mathrm{pH} 6.7,50 \mathrm{mM}$ sodium chloride. Data analysis was performed using ASTRA.

NMR Spectroscopy and Spectral Assignments. NMR experiments were performed on unlabeled, ${ }^{15} \mathrm{~N}$ enriched or ${ }^{13} \mathrm{C}$ and ${ }^{15} \mathrm{~N}$ enriched Psb27 samples $(\sim 0.5 \mathrm{mM})$ in sodium phosphate buffer $(20 \mathrm{mM}, \mathrm{pH} 6.7)$, in the presence of $50 \mathrm{mM}$ sodium chloride, $5 \mathrm{mM}$ TCEP, $5 \% \mathrm{D}_{2} \mathrm{O}$ and $0.02 \%$ sodium azide. Spectra were recorded at $25^{\circ} \mathrm{C}$ on Bruker AV-500 and AV-800 spectrometers equipped with cryogenically cooled probes, operating at 500 and 800 $\mathrm{MHz}$, respectively. A series of heteronuclear 3D NMR experiments were recorded using ${ }^{13} \mathrm{C}$, ${ }^{15} \mathrm{~N}$ labeled Psb27 protein (S2). Spectra were processed using TOPSPIN (Bruker AG, Karlsruhe, Germany) and analyzed using XEASY (S3).

Resonance Assignment and Structure Determination. The favorable NMR line widths and solution stability found for Psb27 and 5 additional N-terminal residues, (GPLGS, arising from cloning artifacts) allowed spectral acquisition and chemical shift assignment to proceed. The ${ }^{1} \mathrm{H},{ }^{15} \mathrm{~N}$, and ${ }^{13} \mathrm{C}$ resonance assignment of the backbone and side-chains of Psb27 was completed using standard multidimensional heteronuclear NMR techniques $(S 2)$. Complete backbone resonances and $99.6 \%$ of all non-exchangeable side chain resonances were assigned. 
Distance and Dihedral Angle Restraints. Distance restraints were measured from the $100 \mathrm{~ms}$ mixing time 3D ${ }^{15} \mathrm{~N}$-edited NOESY, ${ }^{13} \mathrm{C}$-edited NOESY and 2D NOESY spectra. Hydrogen bond constraints were applied within $\alpha$-helices and the $\beta$-sheet at a late stage of the structure calculation. Both $\phi$ and $\psi$ backbone torsion angles were derived using TALOS (S4). Dihedral angle restraints for $\phi$ and $\psi$ angles were used as summarized in Table S1.

Structure Calculation and Analysis. Initial structures were calculated using CYANA 2.1 (S5) and then refined with Xplor-NIH (v 2.22) (S6). The coordinates of the 20 conformers that represent the solution structure of Psb27 and the experimental constraints have been deposited in the Protein Data Bank (PDB code 2KMF). Structural statistics for the final set of 20 structures, selected from the 256 calculated structures on the basis of their stereochemical energies, are presented in Table S1. They are energetically reasonable and display acceptable covalent geometry with $99.3 \%$ of residues lying in allowed areas of the Ramachandran plot. PROCHECK_NMR (S7) and MOLMOL (S8) were used for the analysis of structure quality. The final structures had no experimental distance violations greater than $0.30 \AA$ or dihedral angle violations greater than $5.0^{\circ}$.

Sequence Alignment and Analysis. Sequences were found by a BLAST (S9) search of the NCBI sequence database and aligned using Clustal-W (S10). Signal sequences were identified using DOLOP $(S 11, S 12)$ for the cyanobacterial sequences and a report by Peltier and co-workers (S13) for the Arabidopsis thaliana sequence and removed. A search for structural homologs of Psb27 in the Protein Data Bank was performed using secondary structural matching as described in $(S 14)$. Structure alignment was performed using TOP $(S 15)$.

Prediction of Interaction Sites and Docking Simulations. To identify regions on Psb27 that were likely to mediate interactions with other proteins sites SHARP2 was used (S16). Positions identified included the P- $\Phi-P$ motif (Pro86, Ile87, Pro88), three conserved residues 
belonging to the polar patch (Thr70, Tyr78, Tyr82) and a number of non-conserved polar residues on helices 3 and 4 (Thr66, Ser74, Ser81, Arg85, Glu89, Lys90). A large cluster of residues at the N-terminal end of helix 1 (Thr5 to Gln13) and the adjacent C-terminal region of helix 2 (Arg52-Kys56) together with the C-terminal end of helix 4 (Thr100 to Val110) were also identified as a potential binding site.

Docking simulations were used to determine whether the existing crystal structures of PSII present surfaces complementary to the solution structure of Psb27. The structure of Psb27 presented here was docked to the PSII crystal structure using the PDB entry 3BZ1 (S17). Residues 5 to 110 of Psb27 were used in the search. A monomer from the PSII structure was used, and for most searches the extrinsic proteins PsbO, PsbU and PsbV were omitted. GrammX and PatchDock $(S 18, S 19)$ were used for the docking calculations. The majority of positions ranked as favorable binding sites in these calculations were on the cytoplasmic rather than lumenal side of PSII which is inconsistent with previously published biochemical data $(S 20)$. Two of the top ten solutions from PatchDock identified a site on the lumenal surface of PSII, and this overlapped the PsbV binding site. However, GrammX produced no solutions with Psb27 on the lumenal side of PSII. The lack of any biochemical evidence, particularly mutational data, defining specific residues on PSII or Psb27 as potential interaction sites and an insufficient understanding of the components or oligomeric state of PSII in its Psb27 binding mode limits the accuracy of any model. 
Table S1. Summary of restraints and structural statistics for the 20 lowest energy structures of

$\mathrm{Psb} 27$ in aqueous solution at $\mathrm{pH} 6.7$ and $25^{\circ} \mathrm{C}$

\section{Experimental constraints}

Total

Intraresidue

Sequential $(|\mathrm{i}-\mathrm{j}|=1)$

Short range $(1<|\mathrm{i}-\mathrm{j}|<5)$

Long range $(|i-j| \geq 5)$

Hydrogen bonds

Dihedral angles $(\phi, 84 ; \psi, 84)$

Rmsd from experimental distance restraints $(\AA)$

$0.0018 \pm 0.001$

Rmsd from experimental dihedral restraints $\left(^{\circ}\right)$

\section{Rmsd from idealized covalent geometry}

Bonds $(\AA)$

$0.003 \pm 0.0001$

Angles $\left({ }^{\circ}\right)$

$0.495 \pm 0.013$

Impropers $\left(^{\circ}\right)$

$0.345 \pm 0.010$

\section{Measures of structural quality}

$\mathrm{E}_{\mathrm{LJ}}\left(\mathrm{kcal} \mathrm{mol}{ }^{-1}\right)$

Procheck percentage residues in region of Ramachandran plot

(residues with $\mathrm{S}(\phi)$ and $\mathrm{S}(\psi) \geq 0.9$ : total, 102)

Most favourable

Additionally allowed

Generously allowed

Disallowed

Angular order: residues with $\mathrm{S}(\phi) \geq 0.9$

105

$$
\text { With } \mathrm{S}(\psi) \geq 0.9
$$

104

Overall G-factor

Bad contacts/ 100 residues

Violations

Experimental distance constraints $>0.30 \AA$

0

Experimental dihedral constraints $>5.0^{\circ}$

0

\section{Coordinate precision}

Mean pairwise RMSD $(\AA)$

$\mathrm{C}^{\alpha}, \mathrm{C}, \mathrm{N}$

All heavy atoms

Residues 1-110

$1.17 \pm 0.39$

$1.61 \pm 0.27$

Regular secondary structure ( $\alpha 1-\alpha 4)$

$0.36 \pm 0.07$

$1.16 \pm 0.10$ 


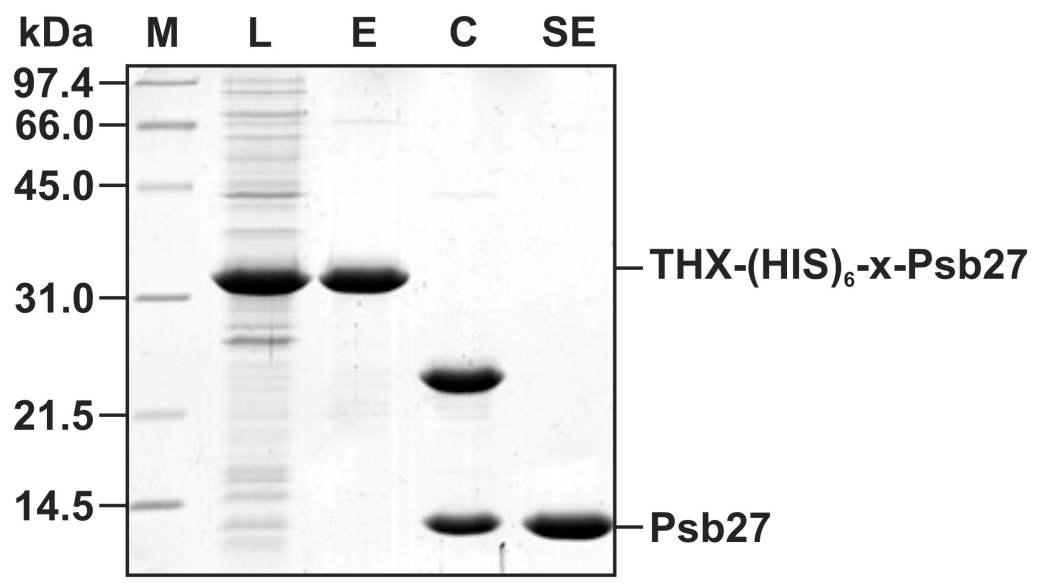

FIGURE S1. Purification of THX-(His) $)_{6}-\mathbf{x}-\mathbf{P s b 2 7}$. Fractions collected at key steps of the purification were analyzed by SDS-PAGE. Lanes are: clarified lysate (L); eluate from IMAC column (E); PreScission protease cleavage products (C), and fractions eluting at $72-88 \mathrm{~mL}$ from the Superdex-75 16/60 column (SE). 


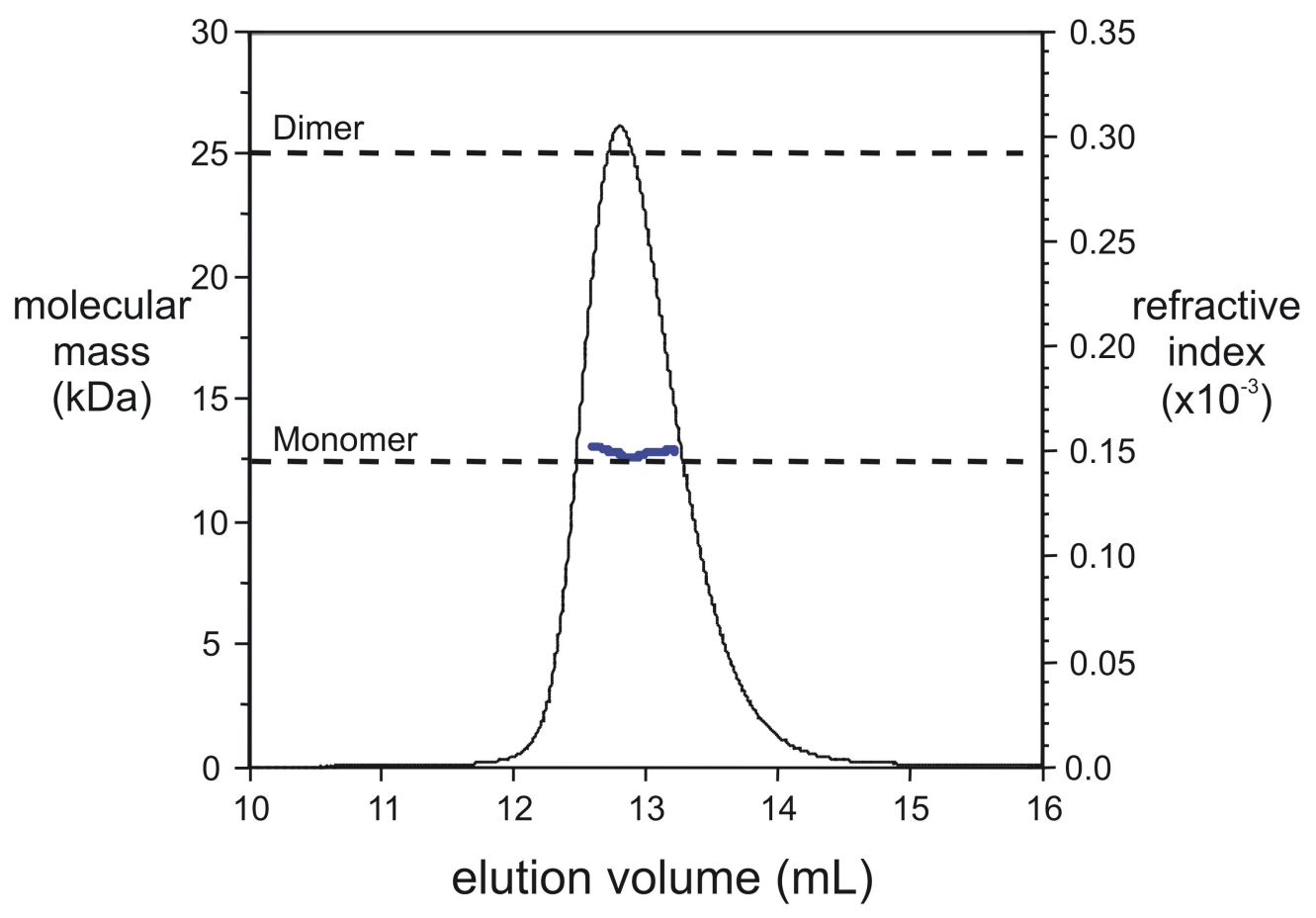

FIGURE S2. Psb27 is a monomer. Purified Psb27 was analysed by MALS following separation on a Superdex-75 size exclusion column. The refractive index (black line) as a function of elution volume and the derived molecular mass of the peak is shown (blue points). The calculated molecular mass of monomeric and dimeric recombinant Psb27 is indicated with dashed lines. 


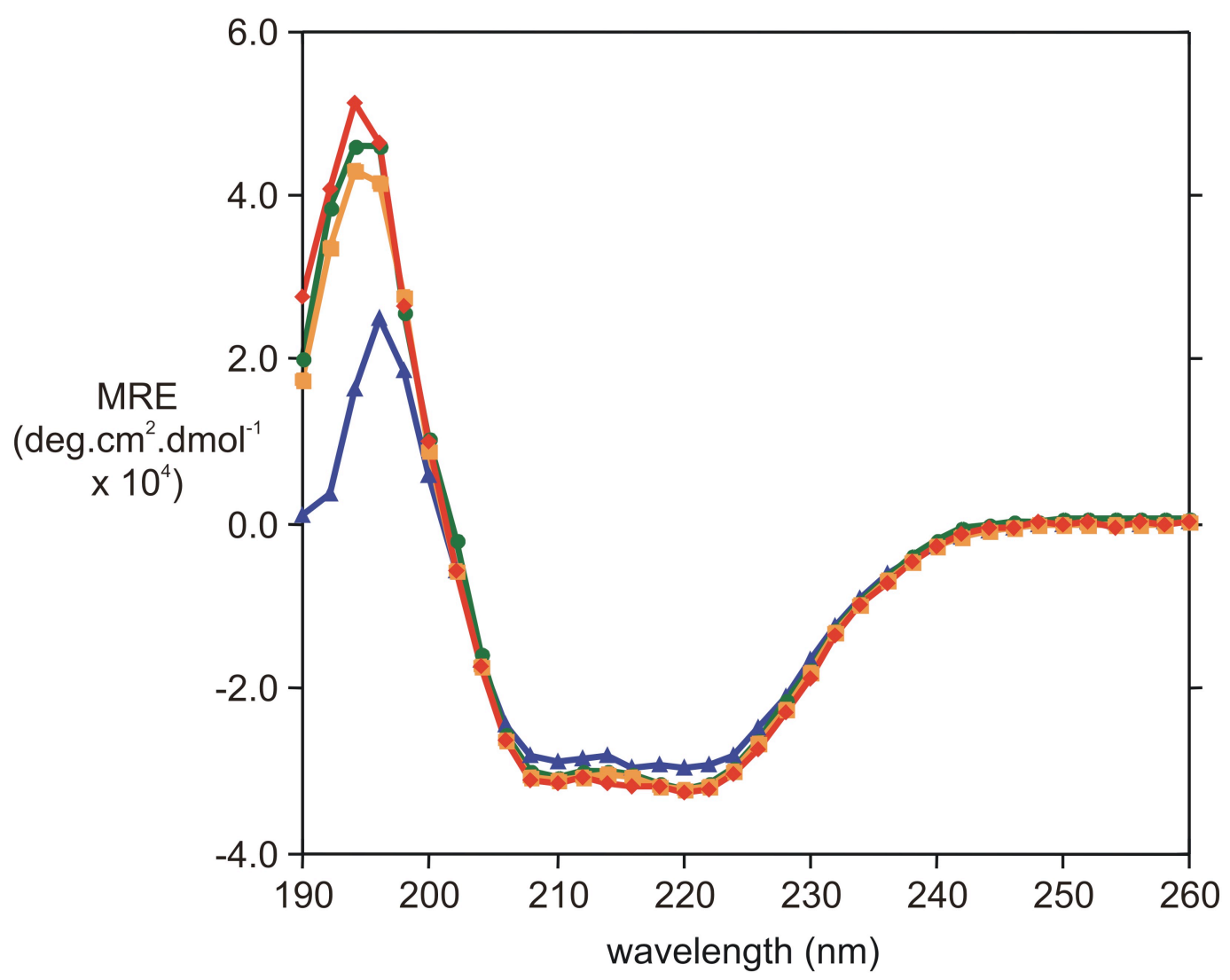

FIGURE S3. Circular dichroism analysis of Psb27. Spectra of Psb27 were acquired at $20^{\circ} \mathrm{C}$ in $20 \mathrm{mM}$ sodium citrate/phosphate $\mathrm{pH} 3.5(\diamond), 5.5(\square) 7.5(\bigcirc)$ or Tris-phosphoric acid pH $9.0(\Delta)$. Mean residue ellipticity (MRE $\operatorname{deg} \mathrm{cm}^{2} \mathrm{dmol}^{-1}$ ) was measured as a function of wavelength every $2 \mathrm{~nm}$. Each curve is the baseline subtracted mean of five scans. 
A

Synechocystis PCC6803 $P$. marinus MIT9313 P. marinus MIT9515 P. marinus SS120 Synechococcus WH8102 Synechococcus WH7803 Synechococcus RCC307 Anabaena PCC7937 Synechococcus PCC7942 T. erythraeum IMS1 T. elongatus $\mathrm{BP}-1$

Synechocystis PCC6803 P. marinus MIT9313 P. marinus MIT9515 P. marinus SS12 Synechococcus WH8102 Synechococcus WH7803 Synechococcus RCC307 Anabaena PCC7937 Synechococcus PCC7942 T. erythraeum IMS1 T. elongatus $\mathrm{BP}-1$

B

Synechocystis PCC6803

$P$. trichocarpa

$R$. communis

V. vinifera

A. thaliana

Z. mays

O. sativa

P. sitchensis

P. patens

Synechocystis PCC6803

P. trichocarpa

$R$. communis

V. vinifera

A. thaliana

z. mays

o. sativa

P. sitchensis

P. patens
1

10

20

30

40

50

----CDSGTGLTGNYSQDTLTVIATLREAIDLPQDAPNRQEVQDTARGQINDYISRYRR 55 -NGSANAAEIQLSGNYVDDTVNVAHNLQDAIALSSDDEGFSAAQEEARDLSNDYISRYRR 59 FNSPSYAAKTSMTGDYTQDTISVVKTLQIAVDTPKDSPNKNEVRDESLALITDYISRYRN 60 FGQSLAAAKPFMSGDFAKDTVSVAQSLKETIALSDDDGQLSESKDEALALITAYISRYRN 60 ---CSGDAEARLTGDYVEDTIAVAHNLREVIDLPQDAANRGEAESEARALINDYMSRYRP 57 ---CGDSTTSLLSGDYVEDTVAVVHMLQNTLALPADAESLQDSEHEAHDLINDYMSRYRP 57 ----CGGTPSGLTGTYVDDTVSVAKSLLSI IAP-EDGQAS SEQQQARDLIYNYIARYRP 55 ----CGSPDSLTGDYRQDTLAVVNTLRQALEITEDSPDKAALQAEARQKINDFSARYQR 55 ---CTGGGDSAISGNYRQDTLAVVTSLRNAITLPDDAPEKSAAQAEARQLINDFAARYRR 57 ----CSN-PSTLSGNYSEDTLSLINSLKTAIELPENTEAKSEAQAIARQAINDYASRYRR 55 ----CANVPTGLTGNFREDTLALISSLREAIALPENDPNKKAAQAEARKKLNDFFALYRR 56 $::^{\star}: \quad: \quad: \quad: \quad{ }^{\star}:$

60 70 80 90 100 110

KGDAGGLKSFTTMQTALNSLAGYYTSYG-ARPI PEKLKKRLQLEFTQAERSIERGV-- 110 RSKVNNLQSFTTMQTALNSLAGHYNNFA-NRPLPEELQNRITKELAKAEQTVLRGR-- 114 RGMVNKTQSFTTMQTALNAMAGHYKNFA-TRPLPDKLKERLTKEFSLAEKMVLRES-- 115 RPQVNGTSSFTTMQTALNAMAGHYKTFS-NRPLPENLKERLNKELTRAEKVVAKEI-- 115 QPRVNGLSSFTTMQTALNSLAGHYASYA-NRPLPEALHDRIAKELGKAEKSAVRGS-- 112 RPQVNGLSSFTTMQTALNSLQGHYNTYT-NRPVPEALKTRVEKELSKAEKAALRGT-- 112 NSRVNGLASFTTMQTALNSLAAHYASYN-NRPLSDDLRARLEKELHKAELSVVRGS-- 110 VNSVSGLNSFTTMRTALNSLAGHYSSYP-NRPVPQKLKSRLEQEFKQVESALKRGA-- 110 DSRVSGLSSFTTMQTALNSLAGHYSSYP-NRPVPEKLKKRLEKEFRMVELALNREA-- 112 DNSVSSLPSFTTMRTALDSLAGHYSSYP-NRPVPDKLKKRLAQEFKQVELALKRGV-- 110 DDSLRSLSSFMTMQTALNSLAGHYSSYP-NRPLPEKLKARLEQEFKQVELALDREAKS 113

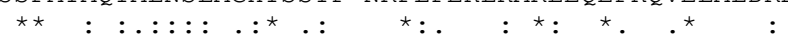
1
10
20
30
40
50

-----CDSGTGLTGNYSQDTLTVIATLREAIDLPQDAPNRQEVQDTARGQINDYISRYRR 55 -----TPAFAGSDEEYVKDTEDVINKVRTTVNMDKNDPNVADAVANLRETSNSWVAKYRR 55 ---PVVPALAASDEEYVKETGEVIDKIRSTINMEKNDPNVATAVAELRETSNSWVAKYRR 57 ----AQAVAANDEEYVKETADVINKVRTTINMDKTDPDVATAVADLRDASNSWVAKYRR 55 --------AEDEEYIKDTSAVISKVRSTLSMQKTDPNVADAVAELREASNSWVAKYRK 50 ----GAARAA-DEEYVSETKEVIGKVRSTINLDKSDPSVADAVAELRELSNSWVAKYRR 54 ----GAARAASDDEYVSETKDVIGKVRSTINMDRADPGVADAVAELRELSNSWVAKYRR 55 ----APAKASLEEDYSKETKEVINQVKSTIDMEKSNPNTSAAVAALRETSNNWVAKYRR 55 ----------DEDYKSETQDMIGQVRSTLAMEKTDPNKAAAVAKLRQSGNEWVAKYRK 48 $:{ }^{*}: \quad: \quad: \quad:$ * $:$

60 70

80

90

100

110

KGDAGGLKSFTTMQTALNSLAGYYTSYG-ARPIPEKLKKRLQLEFTQAERSIERGV-- 110 EKALLGRASFRDMYSALNAVTGHYVSFGPTAPI PSKRRARILEEMDTAEKALSRGR-- 111 EKTLLGRTSFRDIYSALNAVSGHYISFGPTAPI PAKRKARILEEMDSAEKALLRGR-- 113 EKALLGRPSFRDMYSALNAVSGHYISFGPTAPIPAKRKARILEEMDTAEKALLRGR-- 111 EKALLGKASFRDIYSALNAVSGHYVSFGPTAPI PAKRKARI LEEMETAEKALTRGR-- 106 EKSLLGRPSFREMYSALNAVSGHYISFGPTAPIPAKRRARILEEMDTAEKALLRGR-- 110 EKSLLGRPSFREMYSALNAVSGHY ISFGPTAP I PNKRRARILEEMDTAEKALLRGR-- 111 EKQLAGKPSFSNMYSVLNAISGHYISFGPTSPIPAKRKARILEEMDVAEKALSKGR-- 111 AKKVAGKPSFSNMYSVINAISGHYVSFGATYPIPAKRKDRILDEVKDAEKALNRGR-- 104

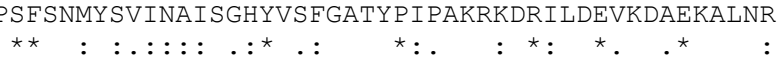

FIGURE S4. Comparison of Psb27 protein sequences. Combined alignment of plant and cyanobacteria Psb27 sequences was made to determine the sequence conservation between phyla. The N-terminal cysteine of Psb27 from Synechocystis sp. PCC 6803 is the first residue of the solution structure and has been assigned as residue 1 in the alignments. (A) Comparison of Psb27 protein sequences from cyanobacteria. (B) Comparison of Psb27 amino acid sequences from plants. Alignments were made using CLUSTAL-W (S10) and the 
numbering is according to the Synechocystis sp. PCC 6803 sequence. Below each alignment, residues completely conserved in both part A and B are indicated (*), residues with only conservative changes are indicated (:) and less-conservative substitutions are indicated by (.). The cyanobacteria Psb27 alignment is comprised of sequences (accession codes are given in brackets) from Synechocystis sp. PCC 6803 (P74367), Prochlorococcus marinus MIT9313 (Q7TUU3), Prochlorococcus marinus MIT9515 (A2BVG9), Prochlorococcus marinus SS12 (AE017126), Synechococcus sp. WH8102 (Q7U5D5), Synechococcus sp. WH7803 (A5GJD2), Synechococcus sp. RCC 307 (CT978603), Anabaena variabilis PCC 7937 (Q3MFN4), Synechococcus elongatus PCC 7942 (Q31RE4), Trichodesmium erythraeum IMS101 (Q114S4), and Thermosynechococcus elongatus BP1 (Q8DG60). In (B) the Nterminus of processed Arabidopsis thaliana Psb27 was taken from Ref (S13). The alignment is comprised of sequences from Populus trichocarpa (XP_002306756), Ricinus communis (EEF50160), Vitis vinifera (XM_002277753), Arabidopsis thaliana (Q9LR64), Zea mays (NM_001154154), Oryza sativa (Q10LV7), Picea sitchensis (ABK23991), and Physcomitrella patens subsp. patens (XM_001770867). 


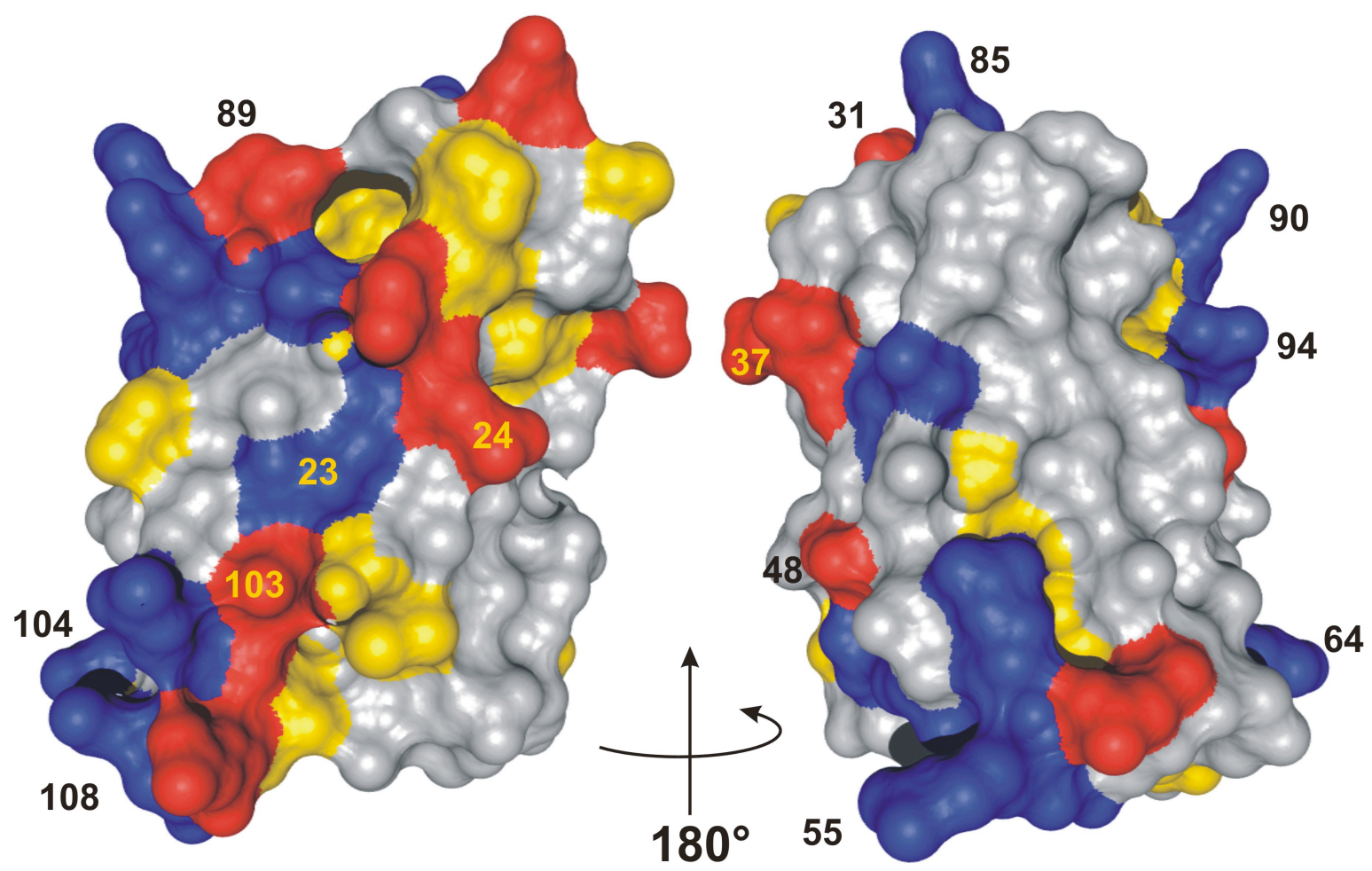

FIGURE S5. Surface exposed charged and hydrophobic residues. Red, acidic; blue, basic; yellow, hydrophobic (Phe, Ile, Leu, Met, Pro, Val). The views are the same as Figure 3. 


\section{REFERENCES}

S1. Bollag, D. M., Rozycki, M. D., and Edelstein, S. J. (1996) Protein Methods. Wiley, New York.

S2. Sattler, M., Schleucher, J., and Griesinger, C. (1999) Heteronuclear multidimensional NMR experiments for the structure determination of proteins in solution employing pulsed field gradients. Prog. Nucl. Magn. Reson. Spectrosc. 34, 93-158.

S3. Bartels, C., Xia, T. H., Billeter, M., Güntert, P., and Wüthrich, K. (1995) The program XEASY for computer-supported NMR spectral analysis of biological macromolecules. J. Biomol. NMR 6, 1-10.

S4. Cornilescu, G., Delaglio, F., and Bax, A. (1999) Protein backbone angle restraints from searching a database for chemical shift and sequence homology. J. Biomol. NMR 13, 289-302.

S5. Güntert, P. (2004) Automated NMR structure calculation with CYANA. Methods Mol. Biol. 278, 353-378.

S6. Schwieters, C. D., Kuszewski, J. J., Tjandra, N., and Clore, G. M. (2003) The XplorNIH NMR molecular structure determination package. J. Magn, Reson. 160, 65-73.

S7. Laskowski, R. A., Rullmann, J. A, C., MacArthur, M. W., Kaptein, R., and Thornton, J. M. (1996) AQUA and PROCHECK-NMR: Programs for checking the quality of protein structures solved by NMR. J. Biomol. NMR 8, 477-486.

S8. Koradi, R., Billeter, M., and Wüthrich, K. (1996) MOLMOL: A program for display and analysis of macromolecular structures. J. Mol. Graphics 14, 51-55.

S9. Altschul, S. F., Madden, T. L., Schaffer, A. A., Zhang, J. H., Zhang, Z., Miller, W., and Lipman, D. J. (1997) Gapped BLAST and PSI-BLAST: a new generation of protein database search programs. Nucl. Acids. Res. 25, 3389-3402. 
S10. Larkin, M. A., Blackshields, G., Brown, N. P., Chenna, R., McGettigan, P. A., McWilliam, H., Valentin, F., Wallace, I. M., Wilm, A., Lopez, R., Thompson, J. D., Gibson, T. J., and Higgins, D. G. (2007) Clustal W and clustal X version 2.0. Bioinformatics 23, 2947-2948.

S11. Madan Babu, M., and Sankaran, K. (2002) DOLOP — database of bacterial lipoproteins. Bioinformatics 18, 641-643.

S12. Babu, M. M., Priya, M. L., Selvan, A. T., Madera, M., Gough, J., Aravind, L., and Sankaran, K. (2006) A database of bacterial lipoproteins (DOLOP) with functional assignments to predicted lipoproteins. J. Bacteriol. 188, 2761-2773.

S13. Peltier, J. B., Emanuelsson, O., Kalume, D. E., Ytterberg, J., Friso, G., Rudella, A., Liberles, D. A., Soderberg, L., Roepstorff, P., von Heijne, G., and van Wijk, K. J. (2002) Central functions of the lumenal and peripheral thylakoid proteome of Arabadopsis determined by experimentation and genome-wide prediction. Plant Cell 14, 211-236.

S14. Krissinel, E., and Henrick, K. (2004) Secondary-structure matching (SSM), a new tool for fast protein structure alignment in three dimensions. Acta Cryst. D60, 2256-2268.

S15. Lu, G. G. (2000) TOP: a new method for protein structure comparisons and similarity searches. J. Appl. Cryst. 33, 176-183.

S16. Jones, S., and Thornton, J. M. (1997) Prediction of protein-protein interaction sites using patch analysis. J. Mol. Biol. 272, 133-143.

S17. Guskov, A., Kern, J., Gabdulkhakov, A. Broser, M., Zouni, A., and Saenger, W. (2009) Cyanobacterial photosystem II at 2.9- $\AA$ resolution and the role of quinones, lipids, channels and chloride. Nat. Struct. Mol. Biol. 16, 334-342.

S18. Tovchigrechko, A., and Vasker, I. A. (2006) GRAMM-X public web server for protein-protein docking. Nucl. Acids Res. 34, W310-314. 
S19. Schneidman-Duhovny, D., Inbar, Y., Nussinov, R., and Wolfson, H. J. (2005) PatchDock and SymmDock: servers for rigid and symmetric docking. Nucl. Acids Res. 33, W363-367.

S20. Roose, J. L., Wegener, K. M., and Pakrasi, H. B. (2007) The extrinsic proteins of photosystem II. Photosynth. Res. 92, 369-387. 